\title{
Letters
}

Website: bmj.com

Email: letters@bmj.com

\section{Doctors in Guantanamo Bay are at risk of being accessories to torture}

Recent events make me concerned on behalf of my medical colleagues in the US military forces. I have imagined what I might do if I were to find myself posted to Guantanamo Bay in Cuba. Perhaps I would pen a letter to the $B M J$ because of its keen interest in medical human rights issues.' This is the sort of letter I might write.

EDITOR-I have been posted to the US military base at Guantanamo Bay. I will be expected to provide medical care to the hundreds of prisoners being relocated from Afghanistan. I am told that they are coming to Cuba for intensive interrogation.

I am under no illusion: this is a euphemism for brutal treatment and torture. ${ }^{2}$ It is widely believed-in Central and South America at least-that interrogations sponsored by the CIA and US military incorporated violence ranging from beatings to cycles of drowning. As a doctor, should I resuscitate prisoners so that they might be retortured? I would appreciate your advice.

My Alter Ego

We can ill afford to assume that inhumane treatment is sponsored only in countries where democracy and respect for human rights are not secure. Given the backing of the UK and US governments for detaining prisoners in Guantanamo Bay, we can also no longer assume that doctors placed in such unfortunate positions can rely on the support of the democratic world.

The $B M J$ could fulfil a useful function in debating this issue and offering advice and support to our unfortunate US colleagues.

Tom Marshall lecturer in public health medicine Banbury OX17 3PG

1 Nathanson V. Doctors and torture. BMJ 1999;319:397-8

2 Rosenberg C. Briton is among Al Qaeda chain gang. Mail on Sunday 2002 Jan 13:24-5.

\section{Non-sexual transmission of HIV has been overlooked in developing countries}

EDIToR-Accumulating evidence undermines the belief that heterosexual transmission in developing countries has as largeand that unsterile medical equipment has as little-a role as supposed by many HIV experts. In 1983 the World Health Organization identified contaminated sharps-but not heterosexual promiscuity-as a risk factor for HIV in tropical countries. ${ }^{1}$ During the next five years, however, high rates of HIV infection were reported in female sex workers and patients at clinics for sexually transmitted diseases.

By the late 1980s a consensus had emerged that more than $90 \%$ of adult HIV infections in sub-Saharan Africa were attributable to heterosexual contact, and only about $2 \%$ to contaminated sharps. This consensus was forged in the absence of empirical studies controlling for confounding between sexual and medical exposures, and despite the fact that unsafe injections are common in developing countries. ${ }^{23}$ More important, inquiry into iatrogenic transmission all but disappeared from the HIV research agenda, and routine epidemiological reports from developing countries-not to mention meta-analyses and evaluations of intervention trials-have often been silent about non-sexual transmission. ${ }^{45}$

The literature indicates that researchers have undervalued data pointing to a significant role for medical transmission. Many studies, particularly from Africa, report unexplained high rates of HIV incidence during antenatal and postpartum periods, implicating nosocomial exposure. They also report that $20-40 \%$ of HIV infections can be attributed to injections by univariate population attributable risk calculations; non-trivial rates of HIV in sexually inexperienced adults; and many HIV positive children with HIV negative mothers. ${ }^{\mathrm{w1}-30}$ In addition, the frequent lack of association between sexual behaviour variables and HIV trends, and the low rate of penovaginal HIV transmission in studies of serodiscordant couples in Africa as elsewhere, suggest a need to reassess the contribution of heterosexual exposure.

Although cofactors such as sexually transmitted diseases and lack of circumcision may boost heterosexual transmission, the levels of such covariates and their known influences on transmission do not seem sufficient to explain Africa's HIV epidemic. In 1999 public and private international health organisations formed the Safe Injection Global Network (SIGN), currently headquartered at WHO, to promote injection safety. Our view, which suggests a pivotal role for contaminated sharps in the global HIV catastrophe, supports the network's efforts to reduce unnecessary and unsterile injections. Adding such interventions to efforts for HIV prevention may bring greater success than has been achieved to date with a narrow focus on condoms and heterosexual transmission.

David Gisselquist independent consultant

29 West Governor Road, Hershey, PA 17033, USA

Richard Rothenberg professor

Department of Family and Preventive Medicine,

Emory University School of Medicine, 69 Butler

Street SE, Atlanta, GA 30303, USA

John Potterat independent consultant

301 South Union Blvd, Colorado Springs,

CO 80910, USA

Ernest Drucker professor of epidemiology and social medicine

Department of Epidemiology and Social Medicine, Montefiore Medical College and Albert Einstein College of Medicine, 111 East 210th Street, Bronx, New York 10467-2490, USA

\section{Peferences w1-30 are available on bmj.com}
1 World Health Organization. Acquired immunodeficiency syndrome-an assessment of the present situation in the world: memorandum from a WHO meeting. WHO Bull $1984 ; 62: 419-32$
2 Drucker E, Alcabes PG, Marx PA. The injection century: consequences of massive unsterile injecting. Lancet (in press).
3 Simonsen L, Kane A, Lloyd J, Zaffran M, Kane M. Unsafe injections in the developing world and transmission of bloodborne pathogens. WHO Bull 1999;77:789-800.
4 Rottingen J-A, Cameron DW, Garnett GP. A systematic review of the epidemiologic interactions between classic sexually transmitted diseases and HIV. Sex Transm Dis 2001;28: 579-97.
5 Grosskurth H, Gray R, Hayes R, Mabey D, Waver M. Con- trol of sexually transmitted diseases for HIV-1 prevention: understanding the implications of the Mwanza and Rakai understanding the implications of the Mwanza and Rakai
trials. Lancet 2000;355:1981-7.

\section{Adequate quality of HIV drugs must be ensured}

Editor-A large global health and AIDS fund would have a lasting impact on morbidity and mortality only if the potency of antiretroviral drugs and the quality of diagnostic tools were adequately monitored in the field.

With the exception of ritonavir, antiretroviral drugs require constant storage in a controlled temperature not exceeding 25-30 ${ }^{\circ} \mathrm{C}$. ${ }^{1}$ Inadvertent exposures to extremes of high temperature and humidity can affect drug potency. For example, in Nigeria and Thailand an assessment of the quality of chloroquine, amoxycillin, co-trimoxazole, ampicillin, and cloxacillin-which have similar storage requirements to antiretroviral drugs-found that $35.5 \%$ of samples were substandard. ${ }^{2}$ Six samples of chloroquine contained no active ingredient at all. Substandard and fake drugs are found in 
Latin America, Africa, and Asia. ${ }^{3}$ If the quality of antiretroviral drugs was poor this might lead to therapeutic or prophylactic failure and the emergence of resistant strains of HIV.

Establishing an effective HIV treatment service requires high quality kits and reagents for diagnosing and monitoring HIV/AIDS. The sensitivity and specificity of HIV assays decline if they are inappropriately stored or used after their expiry date. This decline compromises the reliability of blood testing for HIV before blood transfusions. ${ }^{4}$

A global strategy to tackle the HIV epidemic must therefore incorporate regular sampling of drugs for HIV infection and diagnostic laboratory reagents from the field to assess drug potency and the sensitivity and specificity of diagnostic reagents. The addition of chemical stabilisers to drugs and reagents may help to maintain their quality: the least stable of the common childhood vaccines, the oral polio vaccine, is stabilised by the addition of pirodavir and deuterium oxide, which allow it to resist even a 10 hour exposure to $42^{\circ} \mathrm{C}$. ${ }^{5}$

Subhash C Arya research physician

Centre for Logistical Research and Innovation, New Delhi 110048, India

subhashji@hotmail.com

1 Department of Health. British pharmacopoeia: 2001. Vols I, II. London: Stationery Office, 2001.

2 Shakoor O, Taylor RB, Behrens RH. Assessment of the incidence of substandard drugs in developing countries. Trop Med Int Health 1997;2:839-45.

3 Po ALW. Too much, too little, or none at all: dealing with substandard and fake drugs. Lancet 2001;357:1904

4 Consten EC, van der Meer JT, de Wolf F, Heij HA, Henny PC, van Lanschot JJ. Risk of iatrogenic human immunodeficiency virus infection through transfusion of blood tested by inappropriately stored or expired antibody assays in Zambian hospital. Transfusion 1997;37:930-4.

5 Verheyden B, Andrus K, Rombart B Capsid and RNA stabilization of the oral poliovaccine. Vaccine 2001;19:1899905

\section{Therapeutic consultation centres are helpful in developing countries}

EDITOR-The increasing global gap between rich and poor countries leads to inequalities in access to drugs and to the knowledge and skills needed for their rational use. It also leads to qualitatively different information needs.

Therapeutic information on the management of HIV infection and AIDS flows at two separate levels: although some doctors debate about the potential benefits of new viral transmembrane protein blockers, others are wondering how to manage a patient with pneumocystis pneumonia because of insufficient financial resources to purchase co-trimoxazole. These people could benefit from local therapeutic consultation centres, especially in countries where the prevalence of HIV infection and AIDS is high and access to appropriate treatment (not only to triple antiretroviral therapy) is unaffordable.

Therapeutic consultation centres are one of the most relevant service activities of clinical pharmacology, ${ }^{1}$ supplying problem oriented information for inquiries on individual patients or on factual knowledge. ${ }^{2-5}$ In prevention and control programmes for HIV infection and AIDS such a centre specialising in managing these conditions can give quick, expert, and locally focused answers to common problems. For example, it can give advice on prescription and dose adjustments needed in special situations such as pregnancy, paediatrics, and anaemia; best available management for opportunistic infections; confounding side effects (that is, side effects not identified as such); failure to identify drug interactions: best alternatives when there is no drug (or when drugs are scarce or unaffordable); and advice when appropriate treatment proves ineffective.

A therapeutic consultation centre could: - Develop local guidelines

- Develop the content of and tools for undergraduate teaching and continuous education

- Participate in campaigns on general health and sexual education

- Give advice to policy makers, drug regulatory authorities, and healthcare providers on drug selection

- Monitor prescription and use of treatment to identify inappropriate practices, with particular emphasis on outcome research

- Contribute to the management of international drug donations

- Design and conduct studies on specific issues (for example, transferability of the results of clinical trials performed in other settings, identifying subgroups for which evidence is lacking, cultural perceptions, interactions with non-conventional treatments, adherence)

Such a centre would need political will and support from local authorities, training, continuous external support, and funding. It should include people trained in both infectious diseases (particularly HIV infection and AIDS) and clinical pharmacology, an internet connection, and access to essential drug information sources and medical publications. One such centre will be set up in the Dominican Republic with the support of the World Bank as part of the framework of the multicountry HIV/AIDS prevention and control programme for the Caribbean region.

Albert Figueras assistant professor afs@icf.uab.es

Joan-Ramon Laporte professor

Departament de Farmacologia, Terapèutica

Toxicologia, Universitat Auto noma de Barcelona, Barcelona, Spain

1 WHO Working Group on Clinical Pharmacology in Europe. Clinical pharmacology in Europe: an indispensable part of the health service. Eur I Clin Pharmacol 1988;33:535-9.

2 Rodríguez C, Arnau JM, Vidal X, Laporte JR. Therapeutic consultation: a necessary adjunct to independent drug information. BrJ Clin Pharmacol 1993;35:46-50.

3 Davies DM, Ashton CH, Rao JG, Rawlins MD, Routledge PA, Savage RL, et al. Comprehensive clinical dru information service: first year's experience. BMJ 1977;i:8990.

4 Spector R, Heller A, Johnson MW. The structure and function of a clinical pharmacology consulting service. J Clin Pharmacol 1979;19:257-60.

5 Öhman B, Lyrvall H, Alván G, Sjöqvist F Clinical pharm cology and the provision of drug information. Eur J Clin Pharmacol 1992:42:563-8.

\section{Animal studies and HIV research}

\section{Animal studies are inaccurate for HIV research}

EDITOR-As Yamey et al highlighted, HIV will have killed 55 million people by the year 2010. ${ }^{1}$ Now, 20 years since the first appearance of the virus, is a good time to review the advances to date and identify promising avenues for future research.

To estimate the amount of money spent on research on HIV and, within that, the amount spent on animal studies is difficult. Assessments of the efficacy of animal studies in HIV research are, however, easier to come by.

Thomas Insel, former director of the Yerkes Regional Primate Center in Georgia, said: "[An animal model] that takes 12-14 years to develop doesn't sound to me to be ideal ... I can't tell you what it is that those studies [with chimpanzees] have given us that has really made a difference in the way we approach people with this disease."” Animal models of HIV have been notoriously inaccurate for two reasons.

Firstly, the immune response is intensely complicated and there are many disparities between the human immune response and those of other animals. Secondly, viruses are usually species specific.

In terms of treatment, the efficacy of zidovudine - originally an anticancer drugwas shown in 1985 from the results of in vitro studies rather than animal research. Similarly, combination antiretroviral therapy was developed using in vitro methods, rational drug design, and clinical research.

In vitro research has also enabled other advances in understanding and potentially treating HIV. These include elucidating the structure of the virus (and recently the rare b12 antibody), finding that an HIV-1 entry inhibitor could prevent HIV from fusing with the cell membrane, ${ }^{3}$ and discovering that certain strains of HIV do not use the normal 2-receptor binding process but bind directly to T helper cells via the CD8 receptor. ${ }^{4}$ Epidemiological studies determined the routes of HIV transmission. Gene variants that influence HIV progression were identified using longitudinal epidemiological cohort studies, high throughput genotyping and polymorphism discovery methods, and computational algorithms to detect gene associations in cohorts with the disease

The fact that 20 years on there is still no cure or vaccine for HIV is surely partly because too much money, time, and effort have been invested in animal research which has produced little, if nothing, in return. To make any impact on this global pandemic during the next 20 years, funding needs to be concentrated on research methods that have come up with the goods.

Ray Greek president, Americans for Medical Advancment

2251 Refugio, Goleta, CA 93117, USA

Pandora Pound freelance researcher (medical sociology) Radford Mill, Timsbury, Bath BA2 0QF

Competing interests: None declared. 
1 Yamey G, Rankin W, Feacham R. Twenty years of AIDS and no end in sight. BMJ 2001;322:1440.

2 Smaglik. AIDS vaccine researchers turn from chimps to monkeys. Scientist 1999;13:7.

3 Root MJ, Kay MS, Kim PS. Protein design of an HIV-1 entry inhibitor. Science 2001;229:884-8.

4 Saha K, Zhang J, Gupta A, Dave R, Yimen M, Zerhouni B. Isolation of primary $\mathrm{HIV}-1$ that targets $\mathrm{CD} 8+\mathrm{T}$ lymphocytes using CD8 as a receptor. Nat Med 2001;7:65-

5 Ometto L, Zanchetta M, Mainardi M, De Salvo GL, GarciaRodriquez MC, Gray L, et al. Co-receptor usage of HIV-1 mother-to-child transmission. AIDS 2000;14:1721-9.

\section{Reply: Animal models for HIV advance} and complement clinical studies

EDITOR-Overcoming the HIV/AIDS epidemic has presented an unprecedented challenge to the scientific and medical communities. Despite years of research and the development of antiviral drugs, death from AIDS remains a certainty. A safe and effective vaccine is widely acknowledged as the only means to stem the pandemic. The rate of progress to date has underscored the need for multifaceted scientific approaches. In their letter above Greek and Pound discount the value and results gained from using animal models, in conjunction with in vitro and epidemiological studies, for HIV research. Such discounting is unwarranted.

In fact, animal models have provided key advances. Animal studies on HIV allow us to gather information, compare approaches, and perfect strategies to maximise the potential for clinical success. Work in chimpanzees showed that chimpanzees and humans have a similarly long time frame between HIV infection and the development of AIDS. This led to a switch to using macaques, in which AIDS develops sooner, to expedite the testing of new, risky concepts without putting humans in danger.

Before studies were conducted in nonhuman primates short term treatment of newly infected, symptom-free patients immediately after exposure with antiviral drugs was considered to be risky and unlikely to result in long term benefit. Then short term treatment with the antiviral PMPA was found to prevent infection in macaques infected with SIV, clearly showing a benefit from stopping treatment. ${ }^{1}$ Subsequently, many of the critical parameters and limitations of interrupting treatment have been discovered using these models. Further studies in macaques have shown that monoclonal antibodies can block vaginal infection, offering hope for non-toxic treatments. ${ }^{2}$

Innovative strategies for vaccine development, such as DNA vaccines, have also been facilitated by research in macaques. Live attenuated SIV, genetically engineered to eliminate pathogenicity, protects adult macaques from lethal challenge. ${ }^{3}$ While an attenuated HIV vaccine was under consideration for humans, this same highly attenuated SIV vaccine was found to cause AIDS in newborn macaques. ${ }^{4}$ Without these studies, the need for additional safeguards might have been missed-with dire consequences.

The delays in making more effective HIV drugs or vaccines should be blamed on this formidable and elusive virus. Animal models must be used to complement epidemiological and clinical studies in humans. Answers will come faster and the research will cost less if the clinical work is focused on strategies that have been pretested in models. Funding in all arenas is critical to evaluate and accelerate progress-and to prevent disasters.

Nancy L Haigwood director, viral vaccines program Seattle Biomedical Research Institute, 4 Nickerson Street, Seattle, WA 98109, USA

Competing interests: NLH is president of the board of trustees of the Washington Association for Biomedical Research, a non-profit educational organisation whose mission is to advance biomedical research for humans and animals through public education and service to the scientific community. Bischofberger N, et al. Prevention of SIV infection in Bischofberger N, et al. Prevention of SIV infection in
macaques by macaques by (R)-9-(2-phose

2 Mascola JR, Stiegler G, VanCott TC, Katinger $H$ Carpenter CB, Hanson CE, et al. Protection of macaque against vaginal transmission of a pathogenic HIV-1/SIV chimeric virus by passive infusion of neutralizing antibodies. Nat Med 2000;6:207-10.

3 Wyand MS, Manson KH, Garcia-Moll M, Montefiori D, Desrosiers RC. Vaccine protection by a triple deletion mutant of simian immunodeficiency virus. Journal of Viro ogy 1996;70:3724-33.

4 Baba TW, Jeong YS, Penninck D, Bronson R, Greene MF, Ruprecht RM. Pathogenicity of live, attenuated SIV after mucosal infection of neonatal macaques. Science $1995 ; 267: 1820-5$

\section{President Mbeki might have a case on rethinking AIDS}

EdToR-As a prison medical officer in South Africa, I partly agree with President Mbeki's sceptical view of current statistical research into HIV infection and AIDS.

The research data tend to be formulated from actuarial models and short trials in pregnant women attending antenatal clinics. Pregnancy is known to cause a raised rate of false positive results on testing for HIV infection with enzyme linked immunosorbent assay (ELISA). The results of such research lead to frightening statistics, giving the impression that the whole of southern Africa will be depopulated within the next 24 months.

In South Africa's prisons there is a vast overcrowded (often 30 people per cell) population in which homosexuality is widespread and condom use practically nonexistent. This is the perfect breeding ground for the rapid spread of HIV.

Sexually transmitted diseases are common in the prison where I work, and all prisoners who have any such disease are tested for HIV. Prisoners with any other illnesses that do not resolve rapidly (within one to two weeks) are also tested for HIV. As a result, a large number of HIV tests are done every week. This prison, which holds 550 inmates and is always full or overfull, has an HIV infection rate of 2-4\% and has had only two deaths from AIDS in the seven years I have been working there.

The HIV infection rate for all South Africa's prisons is currently 2.3\%. The rate in the prison population should be higher than that in the general population, or at least the same. But the figures for prisons in South
Africa are way below those generated by actuarial models and antenatal data, which purportedly reflect the incidence of infection in the general population.

A widespread mystical attitude towards HIV/AIDS gives this disease recognition out of all proportion to its incidence (compare it, for example, with the number of deaths in southern Africa from malaria, tuberculosis, malnutrition, road crashes, and murders). The legal and ethical implications of this attitude ensure that no statistical research is based on random testing of the general normal healthy population. Data from this kind of research, were anyone brave enough to conduct it, would probably show figures more like those found in the prisons.

Stuart W Dwyer part time district surgeon (forensic medical officer)

Postnet Suite \#5, Private Bag X1672, Grahamstown, 6140 South Africa

swdwyer@eastcape.net

1 Sidley P. Mbeki plays down AIDS and orders a rethink on spending. BMJ 2001;323:650. (22 September.)

\section{Trends in sex differences in mortality from heart disease}

\section{Sex is not same as gender, and theory was} first proposed in 1950s, say authors

EDITOR-In referring to our paper, Editor's choice of 8 September states that "A group from Bristol grabs attention by arguing that the fact that men have much higher rates of heart disease than women may be nothing to do with gender." 2 This shows the current confusion over the use of the words sex and gender

The Oxford English Dictionary (http:// dictionary.oed.com/entrance.dtl) gives the following definition for gender: "Intended to emphasize the social and cultural, as opposed to the biological, distinctions between the sexes." We would agree with this distinction.

In our study we argued that the fact that men have much higher rates of heart disease than women may be nothing to do with sex-that is, biology such as the female hormone oestrogen-but something to do with gender. Indeed, although the data presented in our study cannot test such a hypothesis, in the discussion we raised the possibility that gender differences in dietary habits (related to social and cultural influences on the way that women prepare, eat, and serve food to themselves and men) may be part of the reason why death rates from heart disease differ between women and men.

After our paper was published we discovered a letter published in the Lancet in 1956 that put forward the same theory. ${ }^{3}$ The author's suggestion was based on his observations of variations in the sex difference between different ethnic groups in the United States and between different geographical areas.

Our analysis of secular trends over the past century and contemporary geographical variations suggested to us the same likely 
cause for the emergence of the difference between women and men in the occurrence of coronary heart disease. We were not aware of this letter at the time our paper was published; had we been, we would have cited it.

D A Lawlor $M R C$ research training fellow D.A.Lawlor@bristol.ac.uk

S Ebrahim professor in epidemiology of ageing G Davey Smith professor of clinical epidemiolog Department of Social Medicine, University of Bristol, Bristol BS8 2PR

1 Lawlor DA, Ebrahim S, Davey Smith G. Sex matters: secular and geographical trends in sex differences in coronary heart disease mortality. BMJ 2001;323:541-5. (8 Septem(leart)

2 Editor's choice. Grabbed. BMJ 2001:323. (8 September.)

Keys A. Sex factor in coronary artery disease. Lance 1956;ii:98-9.

\section{Oestrogen may contribute to variation in mortality}

EDITOR-Lawlor et al have outlined geographical and historical variations in sex differences in mortality from coronary heart disease, noting that a higher intake of energy from fat was significantly associated with a higher male:female ratio for mortality from coronary heart disease. ${ }^{1}$ They suggest that these findings cannot be explained by variation in oestrogen concentrations because oestrogen may not, as widely believed, protect against coronary heart disease and, in any case, oestrogen concentrations are not variable across populations or history.

We suggest that the possibility that oestrogen may play a part in explaining their findings cannot be dismissed on either of these counts. A large body of evidence indicates that oestrogen protects women against coronary heart disease (partly by causing less atherogenic serum lipid profiles), and several biochemical pathways by which oestrogen could exert such an effect have been identified. ${ }^{2}$

Studies have shown that ovarian function and oestrogen concentrations differ greatly in different populations. Jasienska and Thune outlined some of the evidence for variation in ovarian function and argued that it is associated with population variation in rates of breast cancer. ${ }^{3}$ Similarly, Bernstein and Ross cited several studies showing low oestrogen concentrations in populations with low rates of breast cancer, including in rural China and rural Japan. ${ }^{4}$ Industrialised countries have seen a trend towards earlier menarche over the past 100 years, ${ }^{5}$ which suggests that the level of ovarian function has been increasing ${ }^{4}$ and that oestrogen concentrations will vary over time as well as geographically.

Several studies have shown a positive association between nutritional status and ovarian function. ${ }^{35}$ Some studies have shown that higher fat intake is associated with higher endogenous oestrogen concentrations. ${ }^{4}$ Thus the relative protection against coronary heart disease afforded to women by oestrogen may be greater in countries with higher fat intake, leading to a bigger gap between male and female mortality from coronary heart disease in such countries.
Correspondingly, the observed positive association between changes in fat consumption and changes in the ratio of male:female mortality from coronary heart disease in England and Wales might be partially explained by changes in oestrogen concentrations protecting women and increasing the male:female mortality ratio when fat intake increased.

In conclusion, a balanced view of the evidence currently available suggests that variation in oestrogen concentrations, between populations and over time, must be considered as at least part of the explanation of Lawlor et al's findings.

Tessa M Pollard lecturer

Department of Anthropology, University of Durham, Durham DH1 3HN

t.m.pollard@durham.ac.uk

Colin Fischbacher lecturer

Nigel Unwin senior lecturer

Department of Diabetes and Department of

Epidemiology and Public Health, Medical School,

University of Newcastle, Newcastle upon Tyne NE2 4HH

1 Lawlor DA, Ebrahim S, Davey Smith G. Sex matters: secular and geographical trends in sex differences in coronary heart disease mortality. BMJ 2001;323:541-5. (8 September.)

Mendelsohn ME, Karas RH. The protective effects of estrogen on the cardiovascular system. $N$ Engl J Med 1999:340:1801-11.

3 Jasienska G, Thune I. Lifestyle, hormones, and risk of breast cancer. BMJ 2001:322:586-7. (15 September) breast cancer. BMJ 2001;322:586-7. (15 September.) cancer risk. Epidemiol Rev 1993;15:48-65.

cancer risk. Epidemiol Rev 1993;15:48-65. 5 Wood JW. Dynamics of human reproduction. New York Aldine de Gruyter, 1994

\section{Diet-heart disease hypothesis is wishful thinking}

EDITOR-Mann et al and $\mathrm{Hu}$ et al list several shortcomings in the trials reviewed by Hooper et al that explain why dietary treatments for patients with coronary heart disease were ineffective. ${ }^{1-3}$ Inferior studies with negative results are prevalent, but where is the positive evidence that justifies the dietary recommendations?

Mann et al point to the improved outcome in the subgroup analysis of the five prolonged trials. But in that analysis Hooper et al excluded the Sydney diet-heart study, where total mortality was significantly increased, and included the Veterans Administration Trial, which was biased by a significant higher number of heavy smokers in the control group.

Mann et al also say that there is an enormous body of descriptive epidemiology that supports the link between dietary fat, cholesterol concentrations, and coronary heart disease. The accumulated epidemiology actually strongly contradicts such a link, as illustrated by a systematic review. ${ }^{4}$ In a study of Japanese migrants in the United States the cultural upbringing was the strongest predictor of coronary heart disease. Those who were brought up in a nonJapanese fashion but preferred the lean Japanese food had a heart attack almost twice as often as those who were brought up in the Japanese way but preferred fatty American food.
Masai people probably have the highest intake of animal fat in the world, but abnormalities on electrocardiography were far less frequent than in Americans and raised atherosclerotic lesions were rare. ${ }^{4}$ Mortality from coronary heart disease in southern India was seven times higher than in the north and the age at death 44 years compared with 52, although people in the north ate 19 times more fat, mostly animal fat, and also smoked much more. ${ }^{4}$

In 30 of 103 time periods in 33 countries fat intake increased along with coronary mortality, but in 33 periods where the intake also increased, coronary mortality was unchanged in 10 and decreased in $23 .{ }^{4}$ In six case-control studies the diet of the coronary patients did not differ appreciably from that of the controls. ${ }^{4}$ In 21 cohort studies including more than 150000 participants with and without coronary heart disease no study found an eating pattern in accordance with the current view on the influence of dietary fat. ${ }^{4} \mathrm{Hu}$ et al have published several studies with similar findings.

But just as is the case with the analysis by Hooper et al, these findings and many other contradictions are always explained away with more or less valid arguments. As Karl Popper would have said: the diet-heart disease hypothesis is unfalsifiable and should therefore be classified as nonscience.

Uffe Ravnskov independent researcher

Magle Stora Kyrkogata 9, S-22350, Lund, Sweden uffe.ravnskov@swipnet.se

1 Mann J, Skeaff M, Truswell S. Dietary fats and prevention of cardiovascular disease. BMJ 2001;323:1000. (27 October.) 2 Hu FB, Sacks F, Willett WC. Dietary fats and prevention of cardiovascular disease. BMJ 2001;323:1000. (27 October.) 3 Hooper L, Summerbell CD, Higgins JPT, Thompson R, Capps NE Davey Smith G, et al. Dietary fat intake and prevention of cardiovascular disease: systematic review $B M J$ 2001:329:757-63.

4 Ravnskov U. The questionable role of saturated and polyunsaturated fatty acids in cardiovascular disease. J Clin Epidemiol 1998;51:443-60.

\section{Does the internet harm health?}

\section{Some evidence exists that the internet does harm health}

EDitor-I would take issue with the statement that there is almost no evidence to support the claim that the internet harms health. ${ }^{1}$ A search of Medline, for example, identifies a report in the Annals of Internal Medicine (www.annalsw.org/issues/v133n11/ nts/200012050-00006.html) that describes the case of a patient who died of kidney and liver failure after using hydrazine sulphate (as recommended by the Kathy Keeton website, www.kathykeeton-cancer.com) as an alternative treatment for cancer. ${ }^{2}$

On another occasion a nurse in the United States was charged with manslaughter after giving MICON-a nontoxic treatment given over 24 hours (www. edensinstitute.com/micom.html)-to 
a patient with cancer (see www.ncahf.org/ digest/01-18.html).

In addition to these examples there are other cases when people find a "cure" on the web and use this, possibly at the expense of conventional treatment. A newspaper article in England (www.thisiswiltshire.co.uk/ wiltshire/archive/2000/11/23/

devizes_news_county2ZM.html) told of a local patient with cancer who raised money to go to a private clinic in Mexico to receive treatment with Laetrile (laevomandelonitrile-beta-glucuronoside). The article quoted local (Mexican) doctors as being "confident" that this would cure the cancer. In contrast, the National Cancer Institute reports that "Laetrile has shown little anticancer activity in animal studies and no anticancer activity in human clinical trials" (www.cancernet.nci.nih.gov/cam/ laetrile.htm).

Medical misinformation is a problem on the internet. The danger is that vulnerable people will adopt these unproved treatments at the expense of proved conventional ones.

Robert Kiley head of systems strategy

Wellcome Library for the History and

Understanding of Medicine, Wellcome Trust,

London NW1 2BE

r.kiley@wellcome.ac.uk

1 Smith R. Almost no evidence exists that the internet harms health. BMJ 2001;323:651. (22 September.)

2 Black M, Hussain H. Fatal hepatorenal failure associated with hydrazine sulfate. Ann Intern Med 2000;133:877-80.

Database of adverse events related to the internet has been set up

EDITOR-Crocco et al's systematic review, mentioned by Smith, ${ }^{1}$ is probably biased by the fact that cases of harm are rarely reported in the peer reviewed literature Recognising this fact, since January 2001 our research unit has collected, on a database, published and unpublished cases of adverse events related to the internet (www.medcertain.org/daeri). We solicit and collect cases submitted by doctors and patients but also include cases reported in lay publications such as newspapers. The cases stored in the database will be published as an aggregate, annual report.

Cases include misdiagnosis or wrong treatments due to online prescription of drugs or medical consulting over the internet; the discontinuation of lifesaving treatments because patients have misinterpreted internet information; the addictive potential of the internet; and the potential of the internet to encourage suicide. As an incentive to submit cases we pay a small honorarium to the submitting doctor.

Although the positive effects on consumer health may well outweigh the negative effects, the medical profession should collect and assess evidence of possible harm much as it collects details of rare but severe side effects of drugs. The eventual aim of the database is to allow qualitative analysis of these stories and to suggest measures to minimise the risks for consumers of health information using the internet
Discussion about the quality of health information on the internet is hampered by our lack of understanding of how consumers digest information and how the mechanism of potential harm operates. We also need such data to conduct further observational and experimental studies investigating possible problems related to the internet and to establish the prevalence of possible problems.

We urge doctors to fill in the questionnaire on the DAERI website if they think they have seen a patient who has been harmed by information or services obtained on the internet.

Gunther Eysenbach project initiator

ey@yi.com

Christian Köhler project officer

Research Unit for Cybermedicine and eHealth,

Department of Clinical Social Medicine, University

of Heidelberg, Heidelberg 69115, Germany

1 Smith R. Almost no evidence exists that the internet harms health. $B M J$ 2001;323:651. (22 September.)

\section{Quinacrine in possible or probable CJD}

\section{If you had suspected CJD would you be indifferent between placebo and quinacrine?}

EDITOR-After the apparent recovery of a patient with suspected variant CreutzfeldtJakob disease when she was treated with quinacrine, the Department of Health is reported as planning a clinical trial to evaluate the drug's effectiveness as a potential treatment for the disease. ${ }^{1}$ Should an ethics committee approve such a trial?

There is clearly considerable uncertainty about the effect of quinacrine in variant Creutzfeldt-Jakob disease and other prion diseases, ${ }^{2}$ but we find it almost inconceivable that a rational patient with suspected prion disease would be in equipoise-that is, indifferent-between quinacrine and placebo. The side effects of quinacrine are well known and are comparatively minor over a wide dose range; the drug penetrates the blood-brain barrier moderately well and has high activity against prions in vitro and in some animal studies. ${ }^{3}$

Prion diseases are invariably fatal when untreated. The balance of risks and benefits is clearly in favour of taking quinacrine (which is cheap and easily available). Any patient prepared to be randomised in a trial of quinacrine versus placebo is likely not to have understood properly what the implications are. Such a trial should not, therefore be sponsored at present, or be approved by ethics committees. It has already been recognised that recruiting patients would be difficult, if not impossible.

The alternative to a randomised trial is a "historically controlled trial." Although diagnosis is tricky, patients classified by the National Creutzfeldt-Jakob Disease Surveillance Unit in Edinburgh as having possible Creutzfeldt-Jakob disease are thought to have a $50-60 \%$ chance of having the disease.
Those classified as having probable Creutzfeldt-Jakob disease are thought to have a $95 \%$ or greater chance of having the disease (R Knight, National CreutzfeldtJakob Disease Surveillance Unit, personal communication).

An ethically acceptable approach would be to offer quinacrine to all patients classified as having possible or probable Creutzfeldt-Jakob disease. It will quickly become apparent, even allowing for the potential biases that can arise from using historical controls, whether quinacrine is preventing the deaths of a large proportion of patients with the disease.

If quinacrine is preventing deaths then trials comparing doses, or combinations of quinacrine and other drugs, could proceed. If, however, it is clearly not saving a majority of patients-for example, if the first 50 patients treated follow courses only a little better than those of historical controls-then the balance of risks and benefits for patients becomes much more equal. Only when an ethics committee judges that fully informed, rational patients would be prepared to enter a trial is it reasonable to allow a trial to proceed.

David Braunholtz senior research fellow

D.A.Braunholtz@Bham.ac.uk

Judith Harris research associate

Department of Public Health and Epidemiology, University of Birmingham, Birmingham B15 2T

1 In Brief: Treatment trial for Creutzfeldt-Jakob disease announced. BMJ 2001;323:650. (22 September.)

2 Lilford RJ, Djulbegovic B. Equipoise and uncertainty principle are not mutually exclusive. BMJ 2001;322:795. (31 March.)

3 Korth C, May BCH, Cohen FE, Prusiner SB. Acridine and phenothiazine derivatives as pharmacotherapeutics for prion disease. Proc Natl Acad Sci 2001;98:9836-41.

4 Young $\mathrm{E}$. First VCJD clinical trial to begin NewScientistYoun .com News Archive.

5 Edwards SJL, Lilford RJ, Braunholtz DA, Thornton J, JackEdwards SJL, Lilford RJ, Braunholtz DA, Thornton J, Jack-
son J, Hewison J. Ethical issues in the design and conduct son J, Hewison J. Ethical issues in the design and conduct
of randomised controlled trials. Health Technology Assessof randomised cont 1998;2:1-96.

\section{It is blinded investigators, not patients,} who must be in equipoise over treatment

EDITOR-Is there not a fundamental misunderstanding about double blind trials in the title of Braunholtz et al's letter about Creutzfeldt-Jakob disease (bmj.com/cgi/ eletters/323/7314/650 and printed here, above)? And a misunderstanding about the meaning of "equipoise"? The authors say, "We find it almost inconceivable that a rational patient with suspected prion disease would be in equipoise ... between quinacrine and placebo."

What one agrees to is not to take a placebo but to take a treatment with a $50 \%$ chance of containing an active ingredient that might be of value. In this way one submits to an unknown fate, but not without hope; one trusts that the blinded investigators are in equipoise as to the risk of alternative fates for your life. A proposed trial of quinacrine seems to meet that criterion.

Ed Cooper consultant paediatrician Newham General Hospital, London E13 8SL Ed.Cooper@nhspeople.net 


\section{WMA should not retreat on use of placebos}

EDITOR-I do not think that patients should remain untreated when a proved effective treatment is available, and I was pleased by the new clause 29 in the revised Declaration of Helsinki. I am dismayed that the World Medical Association is retreating from this position. ${ }^{1}$

The association's first condition for the use of placebo in research trials to be ethically acceptable-"Where for compelling and scientifically sound methodological reasons its use was necessary to determine the efficacy or safety of a prophylactic, diagnostic, or therapeutic method"-is so vague that it could be used to justify any trial using a placebo. For example, to show efficacy we could say that we must have untreated patients. But under the new Declaration of Helsinki, which bans placebo controls when there is an effective treatment, mere efficacy is not enough. It is relative efficacy that is important.

The second condition-"Where a prophylactic, diagnostic, or therapeutic method was being investigated for a minor condition and the patients who received placebo would not be subject to any additional risk of serious or irreversible harm"--suggests that unless the patient might die it is quite acceptable to let him or her suffer. Thus we could use placebos for eczema, for example, and let the patients scratch. I think that patients have a right to be treated. They go to doctors to have their problems alleviated, not to be guinea pigs.

If the reason for back pedalling is the criticism that in developing countries the best established treatment may be too expensive, this is not addressed at all. "Too expensive" is not a scientifically sound methodological reason. We justify trials too small to provide an answer to the question if an adequate trial were too expensive. The relevant clause of the declaration states that "The benefits, risks, burdens and effectiveness of a new method should be tested against those of the best current prophylactic, diagnostic, and therapeutic methods." Inserting the word "available" after "current" would be sufficient to meet the objection of developing countries. If a treatment is too expensive it is not available.

Martin Bland professor of medical statistics St George's Hospital Medical School, London SW17 0RE

mbland@sghms.ac.uk

1 Ferriman A. World Medical Association clarifies rules on placebo controlled trials. $B M J$ 2001;323:825. (13 on placebo
October.)

\section{Authorised clinical staff need access to clinical information}

EDITOR-Rigby et al make the point that it is difficult to ensure appropriate levels of confidentiality in electronic information systems to the point that the highly exacting requirements being demanded by independent commentators and professional bodies are difficult to satisfy without jeopardising the functioning of core services. ${ }^{1}$ It is not clear, however, how the TEAC health project has addressed this problem.

Software from a single supplier should provide a totally integrated system, but it may not contain all the elements required to meet the trust's strategy. A core system together with a number of bespoke systems communicating through integration engines may provide all the requirements. Unfortunately, in my experience, integration is never complete, and password protection is a major problem.

Everyone nowadays has to carry around numerous "passports" in the form of identity cards, keys, smart cards, and passwords. Access is denied without the appropriate passport, and we all know how easy and frustrating it is to lose any of these passports. Computer passwords of at least eight elements are changed at frequent intervals to maintain security. The $\log$ on name is usually specified by the system and can also vary considerably. For a busy clinician, using a different log on name in multiple systems with different and frequently changing passwords, the problem soon becomes impossible. A clinician unable to gain access to a clinical system from a clinical area has three choices.

(1) Call up the information technology department for assistance.

(2) Ask a colleague to log on or reveal the password(s).

(3) Cope without the information technology system by using paper and enter the data later.

I believe that this is a serious and important problem requiring an urgent solution. Ideally this could be solved through a European accreditation system. The examples of health threatening software errors already reported undoubtedly represents the very thin edge of the wedge. Those who are commissioned to introduce health informatics report the perspective of a strong cultural resistance to the technology. A cultural resistance to change as such cannot be supported but a cultural resistance to poor quality is to be commended. Ready access to clinical information systems by authorised clinical staff is a major quality issue and needs to be addressed urgently. The minimal requirements are integration with a single $\log$ on and password and a 24 hour telephone help desk that can remind the clinician of a forgotten password.

David Hutchon consultant obstetrician and gynaecologist

Memorial Hospital, Darlington DL3 6HX DJRHutchon@Postmaster.co.uk

\footnotetext{
1 Rigby M, Forsström J, Roberts R, Wyatt J. Verifying quality and safety in health informatics services. $B M J$ 2001;323;552-6. (9 September.)
}

\section{Surveillance for $S$ aureus bacteraemias is compulsory}

EDIToR-Van Belkum and Verbrugh's editorial on methicillin resistant Staphylococcus aureus (MRSA) focused on the Dutch experience. ${ }^{1}$ It was England that first detected methicillin resistance in $S$ aureus, ${ }^{2}$ and despite the apparent disappearance of these strains in the United Kingdom in the 1970s their descendants are causing problems now.

The first epidemic strain of MRSA, EMRSA-1, seemed to be indistinguishable from that reported from eastern Australian hospitals and caused many hospital outbreaks in the Thames regions, with spread beyond. This was superseded by EMRSA-15 and EMRSA-16, the prevalent strains in England in the 1990s.

Control in the early days was along "search and destroy" lines, but difficulties controlling MRSA in an unsupportive working, political, and financial environment led to the belief that spread was inevitable. In the United Kingdom there was much debate on whether we should "live" with MRSA, using a universal precautions approach. A risk assessment approach, especially protecting high risk areas such as cardiothoracic and orthopaedic wards, was generally favoured. ${ }^{3}$

MRSA accounted for 3984 reported bacteraemias with methicillin susceptibility information in England and Wales in 2000, compared with 66 in 1991-that is, $42 \%$ of $S$ aureus bacteraemias in 2000 compared with $2 \%$ in 1991. The rise has been across all regions and is superimposed on a steady incidence of methicillin susceptible $S$ aureus. These are much worse figures than those in the Netherlands, where infection control teams maintain control largely with the search and destroy approach. The limited published evidence indicates that community MRSA in England still largely reflects spread from hospitals.

The editorial referred to controlling antibiotic use. This is good practice, but the evidence for impact on the control of MRSA is weak. The many confounding factors in the hospital environment make it difficult to evaluate the relation between antibiotic use and the burden of MRSA. ${ }^{4}$ As outbreaks are predominantly of one strain, cross infection probably accounts for a far greater attributable fraction of disease than antibiotic use.

The emergence of a new, more resistant strain (EMRSA-17) in England and the description of glycopeptide resistance in Scotland reduce therapeutic options and highlight the need to raise the profile and resources for infection control. The political climate in England is changing, with growing focus on controlling both infections associated with health care and antimicrobial resistance. This has culminated in the establishment of a compulsory surveillance system for $S$ aureus bacteraemias. ${ }^{5}$

The minister of health undertook that rates of MRSA infection according to hospital activity would be published by named 
acute NHS trusts for 2001. This will clearly focus chief executives' minds on infection control.

Georgia Duckworth head, division of

healthcare-associated infection and antimicrobial resistance

gduckworth@phls.org.uk

Barry Cookson director, laboratory of hospital infection

Andrew Pearson head, nosocomial infection surveillance unit

Natasha Crowcroft consultant epidemiologist,

immunisation division

Public Health Laboratory Service/Communicable Disease Surveillance Centre, London NW9 5EQ

1 Van Belkum A, Verbrugh H. 40 years of methicillin resistant Staphylococcus aureus. BMJ 2001:323:644-5. (22 ant Staphyloco

2 Jevons MP. Celbenin-resistant staphylococci. BMJ $1961 ; i: 124-5$.

3 Working Party Report. Revised guidelines for the control of methicillin-resistant Staphylococcus aureus infection in hospitals. J Hosp Infect 1998;39:253-90.

4 Crowcroft NS, Ronveaux O, Monnet DL, Mertens R Methicillin-resistant Staphylococcus aureus and antimicrobial use in Belgian hospitals. Infect Control Hosp Epidemiol 1999;20:31-6.

5 Department of Health. Surveillance of healthcare associated infections. CMO's Update 2001;30:6.

\section{Latest abolition of limited registration is insulting}

EDITOR-The recent decision by the General Medical Council to abolish the senior doctor route to limited registration is one in a long row of sudden and unannounced changes of the goal posts for overseas and particularly for refugee doctors. ${ }^{1}$

As far as I am aware there has been no warning, and even the most recent $G M C$ News-sent out on the same day as the $B M J$-did not mention this important change. The explanation, however, that most doctors qualified via this route are working (initially?) as senior house officers and therefore need a more broad based examination, adds insult to injury.

It is not the fault of overseas or refugee doctors that British hospitals will not employ senior, albeit foreign qualified and trained, doctors in senior positions. A fair amount of prejudice towards all things foreign prevails in many British institutions, which could often well be described as institutionalised racism. Instead of tackling these prejudices the GMC reinforces them with this recent decision and particularly with the explanation given.

Peter von Kaehne general practitioner

Fernbank Medical Centre, Glasgow G22 6BD

vkaehne@doctors.org.uk

PvK is facilitating a study group of refugee doctors. As a graduate from within the European Union he simply registered without any further examinations.

1 Marchant R. Briefing: Senior doctor route to limited registration abolished. BMJ 2001;323:3. (6 October.)

\section{Doctors' bad press depends on type of newspaper}

EDITOR-Ali et al reported on bad press for doctors. ${ }^{1}$ In a research project with the BMA's public affairs division I analysed all reports on medicine and health science in the 21 major British newspapers published over a period of one month.

Altogether 799 articles were coded into a database and graded according to whether they were positive, negative, or mixed towards, or did not mention, the government, the NHS, individual doctors, and the wider profession. I coded the articles on the basis of a fixed proforma, and when I carried out a blind reliability test on a random series of 30 articles with another coder the total agreement level was $87 \%$.

My data showed a significantly higher proportion of negative articles about individual doctors than positive articles in the tabloids compared with the broadsheets (a ratio of 2.9 compared with $1.4, \chi^{2}=6.244$, $\mathrm{df}=1, \mathrm{P}=0.013)$. When analysing health articles that mentioned the government a similar trend became apparent, with a negative to positive ratio of 6.6 for the tabloids and 2.3 for the broadsheets $\left(\chi^{2}=4.689\right.$, $\mathrm{df}=1, \mathrm{P}=0.030$ ). The difference in the ratio of negative to positive articles about the NHS or the profession as a whole was not significant.

The Daily Mail had a ratio of negative to positive articles of 1.2, closer to the broadsheets than the other tabloids. This possibly suggests that it did not represent a typical tabloid in the study by Ali et al. In comparison $40 \%$ of health articles in the Sun were negative about individual doctors (compared with the average for all papers of $18 \%)$, and the negative to positive ratio was 6.7 .

Negative stories about individual doctors in the tabloids were significantly more likely to generalise to the profession as a whole (in $9.6 \%$ of cases) compared with the broadsheets $\left(1.6 \%\right.$ of the time, $\chi^{2}=4.014$, $\mathrm{df}=1, \mathrm{P}=0.045$ ). These types of articles are dangerous as they can create a link in the reader's mind between one bad doctor and the profession as a whole. It was notable that in this case the Daily Mail did seem anti-doctor- $18 \%$ of articles negative about individual doctors were also negative about the profession.

Although Ali et al concluded that there was no significant change in the ratio of negative to positive articles over time, I believe that I showed that there are significant differences in the ratio across the range of different newspapers. This has important implications regarding the public's opinion of doctors, especially as the Daily Mail, Sun, Express, and Mirror account for $71 \%$ of daily newspaper circulation in Britain.

Christopher Peters final year medical student School of Medicine, University of Leeds, Worsley Building, Leeds LS2 9NL

chris.peters@doctors.org.uk

1 Ali NY, Lo TYS, Auvache V, White PD. Bad press for doctors: 21 year survey of three national newspapers. $B M$ 2001;323:782-3. (6 October.)

\section{A "waiting for investigation" index would be useful}

EDITOR-Oliver raises the point that all stages of the cancer care pathway need speeding up, not just the time taken to see urgent referrals under the two week rule. ${ }^{1}$ We are becoming increasingly concerned about the long delays that many patients experience while they wait for investigations needed before the most appropriate treatment can be decided.

The initial delay to see a hospital consultant, and the time spent on a waiting list for treatment, are nationally audited and familiar to patients, but the third wait-for investigations-is rarely acknowledged. We carried out a postal survey of hospital departments in the northwest of England and found disturbingly long waits for commonly requested investigations.

Over a third of the endoscopy and radiology departments that we contacted quoted waits of over two weeks for urgent tests in cases in which malignancy was suspected. Altogether $8 \%$ of such patients waited over four weeks. Waiting times for tests in cases in which malignancy was thought unlikely but needed to be excluded were longer, with a median of between four weeks and two months and some waits of over eight months. Patients waiting for investigations for benign disease with mild to moderate symptoms fared even worse, with a median wait of over two months and again some waiting over eight months. The waiting time for routine magnetic resonance imaging was over 11 months in one hospital.

In many cases the investigations are essential before treatment can proceed; clinicians have no choice but to delay until the results are known. In other cases, however, the investigations are helpful rather than essential. In these cases the clinician will face the dilemma of whether to proceed to treatment without the investigations, to order an alternative test that could be performed more quickly but would give less helpful results, or to delay treatment until the investigation of choice is done.

Limited resources might be more effective if spent on reducing waiting times for investigations rather than on implementing the two week rule. A "waiting for investigation" index, akin to the cost of living index, might be created to measure the performance of individual trusts and then aggregated into official waiting times for treatments.

Vanessa Pope specialist registrar in general surgery Royal Bolton Hospital, Bolton BL4 0JR pope@doctors.org.uk

P A Sykes consultant surgeon Trafford General Hospital, Manchester M41 5SL

1 Oliver MD. Two week rule for cancer referrals: all stages of care pathway need speeding up. BMJ 2001;323:864. (13 October.

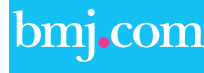

\section{Rapid responses}

Correspondence submitted electronically

is available on our website 